\title{
Response: Commentary: The Impact of the Time Interval Between Radiation and Hyperthermia on Clinical Outcome in Patients With Locally Advanced Cervical Cancer
}

\author{
Johannes Crezee ${ }^{1 *}$, Arlene L. Oei ${ }^{1,2,3}$, Nicolaas A. P. Franken ${ }^{1,2,3}$, Lukas J. A. Stalpers ${ }^{1,2,3}$ \\ and H. Petra Kok ${ }^{1}$ \\ 1 Department of Radiation Oncology, Amsterdam University Medical Centers, University of Amsterdam, Amsterdam, \\ Netherlands, ${ }^{2}$ Laboratory of Experimental Oncology and Radiobiology, Amsterdam University Medical Centers, University of \\ Amsterdam, Amsterdam, Netherlands, ${ }^{3}$ Center for Experimental Molecular Medicine, Amsterdam University Medical \\ Centers, University of Amsterdam, Amsterdam, Netherlands
}

Keywords: radiotherapy, hyperthermia, time interval, DNA damage repair, reoxygenation

\section{A Commentary on}

\section{OPEN ACCESS}

Edited by:

William Small Jr,

Loyola University Chicago,

United States

Reviewed by:

Mark Hurwitz,

Thomas Jefferson University, United States

Andras Szasz,

Szent Istvan University, Hungary

*Correspondence:

Johannes Crezee

h.crezee@amsterdamumc.nl

Specialty section:

This article was submitted to

Radiation Oncology,

a section of the journal

Frontiers in Oncology

Received: 29 November 2019 Accepted: 24 March 2020

Published: 15 April 2020

Citation:

Crezee J, Oei AL, Franken NAP,

Stalpers LJA and Kok HP (2020)

Response: Commentary: The Impact

of the Time Interval Between Radiation

and Hyperthermia on Clinical

Outcome in Patients With Locally

Advanced Cervical Cancer.

Front. Oncol. 10:528.

doi: 10.3389/fonc.2020.00528
Commentary: The Impact of the Time Interval Between Radiation and Hyperthermia on Clinical Outcome in Patients With Locally Advanced Cervical Cancer

by Kroesen, M., Mulder, H. T., Van Rhoon, G. C., and Franckena, M. (2019). Front. Oncol. 9:1387. doi: $10.3389 /$ fonc.2019.01387

Mild hyperthermia $\left(39-43^{\circ} \mathrm{C}\right)$ is an effective radiosensitizer (1). Hyperthermia can eradicate tumor cells, particularly hypoxic cells, independently from timing with radiotherapy, with a clear dose-effect relationship (2-4). Hyperthermia also synergizes more directly with radiotherapy. Temperatures exceeding $39^{\circ} \mathrm{C}$ cause induction of heat shock proteins (HSPs), formation of reactive oxygen species (ROS), decrease in Superoxide dismutase (SOD), enhanced tissue perfusion and reduced oxygen consumption, the latter leading to reoxygenation and enhanced effectiveness of radiotherapy for hyperthermia given before radiotherapy (5-11). Temperatures exceeding $41^{\circ} \mathrm{C}$ cause inhibition of multiple repair pathways of radiotherapy-induced DNA damage if hyperthermia is given shortly before or after radiotherapy $(1,12,13)$. Aforementioned effects all require different timing, sequence and temperature levels, and both time-dependent synergistic and timeindependent additive hyperthermic effects contribute to the effectiveness of clinical hyperthermia (14) as confirmed in an in vivo mouse tumor model (15).

Hyperthermia is clinically proven radiosensitizer for many tumor sites $(16,17)$, including locally advanced cervical cancer (LACC) $(18,19)$. Recently two groups analyzed the impact of time interval on clinical outcome for LACC patients similarly treated with radiotherapy, followed by hyperthermia once a week. Long time intervals are possibly less effective, as radiotherapy-induced DNA damage will get repaired within hours after radiotherapy and for long intervals hyperthermiainduced inhibition of DNA repair can simply come too late to have a therapeutic effect. Our group did find such an impact (20), whereas Kroesen et al. did not (21), sparking a debate on potential reasons including tumor temperature $(22,23)$.

We have therefore read with interest the response of Kroesen et al. (22) on our opinion article "The Impact of the Time Interval between Radiation and Hyperthermia on Clinical Outcome in Patients with Locally Advanced Cervical Cancer" (23), and appreciate their thorough efforts to analyze possible effects of the time interval between radiotherapy and hyperthermia on treatment outcome in LACC patients treated with radiotherapy followed by hyperthermia. They now specifically checked this impact in a subgroup of their cohort in which the highest 
temperature was measured. They did so as van Leeuwen et al. had reported slightly higher tumor temperatures and because their group had reported preclinical results showing a strong dose-effect relationship in inducing inhibition of homologous recombination DNA repair, yielding stronger radiosensitization at higher temperatures (12). However, they could not find any indication that shorter time intervals were clinically more effective than longer intervals, not even in the subgroup with the highest temperatures.

Though looking similar, there may still be differences between the two studies preventing a direct clinically relevant comparison. Among these the fact that higher tumor temperatures were achieved in our group (23), and also the definition of the time interval was different in both studies. Kroesen et al. defined the time interval between EBRT and HT as the time between the first beam-on of the radiotherapy treatment and the start of the heating, that is switching power-on on the HT device (21). This means that fully therapeutic temperature levels exceeding $41^{\circ} \mathrm{C}$ are probably reached $15-30 \mathrm{~min}$ later. In our cohort the time interval was defined as the time between the end of RT and the moment during $\mathrm{HT}$ that $41^{\circ} \mathrm{C}$ was reached, thus our reported time intervals include the initial $15-30$ min warming-up period during the preparation phase of hyperthermia treatment. This was chosen as no inhibition of DNA damage repair will occur when tumor temperatures have not yet reached $41^{\circ} \mathrm{C}(20)$. Our reported time intervals are thus effectively 15-30 min shorter than the intervals reported by Kroesen et al. (21): their "short" interval is close to our "long" time interval. This difference may be clinically relevant depending on how fast DNA repair takes place in the clinical situation. Van Leeuwen et al. established for tumor biopsies of LACC patients, taken at different times after radiotherapy, that all DNA damage is repaired within $2 \mathrm{~h}$ after radiotherapy (20), meaning hyperthermia must be given within $1 \mathrm{~h}$. In contrast, DNA damage had only partially been repaired $4 \mathrm{~h}$ after radiotherapy in in vitro studies in three cervical cancer cell lines (24).

There might be a rationale to consider reversing the sequence and first give hyperthermia, followed by radiotherapy in LACC patients. Reversing sequence yields considerably shorter time intervals become technically feasible as it is no longer needed to heat up the tumor first, which takes at least 15-30 min for deep-seated tumors. Thus, more hyperthermia

\section{REFERENCES}

1. Oei AL, Kok HP, Oei SB, Horsman MR, Stalpers LJA, Franken NAP, et al. Molecular and biological rationale of hyperthermia as radio- and chemosensitizer. Adv Drug Deliv Rev. (2020). doi: 10.1016/j.addr.2020.01.003. [Epub ahead of print].

2. Gerweck LE, Nygaard TG, Burlett M. Response of cells to hyperthermia under acute and chronic hypoxic conditions. Cancer Res. (1979) 39:966-72.

3. Koutcher JA, Barnett D, Kornblith AB, Cowburn D, Brady TJ, Gerweck LE. Relationship of changes in $\mathrm{pH}$ and energy status to hypoxic cell fraction and hyperthermia sensitivity. Int J Rad Oncol Biol Phys. (1990) 18:142935. doi: 10.1016/0360-3016(90)90318-E

4. Wachsberger PR, Burd R, Bhala A, Bobyock SB, Wahl ML, Owen CS, et al. Quercetin sensitizes cells in a tumour-like low effects can contribute, including reoxygenation already effective at temperatures below $41^{\circ} \mathrm{C}(5-7)$. For reversed order the duration of BRCA2 depletion determines the effectiveness of that particular hyperthermia effect, independent of the rate of DNA repair after radiotherapy. This depletion may last longer than the rate with which DNA damage gets repaired. Hypofractionation would increase the number of hyperthermia fractions combined with radiotherapy, while in both LACC protocols hyperthermia was added only once a week. Clinical feasibility of applying such a reversed sequence with hypofractionation and much shorter time intervals has been demonstrated for treatment of recurrent breast cancer (25). Caution is needed when considering optimal sequence and timing for other tumors and combination with radiochemotherapy.

While awaiting more data on clinical DNA repair rates we can conclude that both studies present valid clinical results. Thus, longer time intervals between radiotherapy and hyperthermia are not detrimental for treatment outcome and referral of LACC patients from centers without hyperthermia facilities for hyperthermia treatment in other centers is acceptable. The possible explanation: hyperthermia exhibits multiple working mechanisms, including -besides inhibition of DNA repair- tumor reoxygenation and direct cytotoxicity. Many mechanisms remain fully effective with longer time intervals between radiotherapy and hyperthermia $(5-7,13-15)$. This is also clinically evident for LACC patients, as also with a long time interval the effective contribution of hyperthermia to radiotherapy is of similar magnitude as the contribution of adding chemotherapy to radiotherapy, as demonstrated in the RADCHOC study (26).

So referral for hyperthermia of LACC patients who continue to receive radiotherapy at referring centers is clinically acceptable. We also subscribe to the remark of Kroesen et al. that the strong dose-effect relationship found for hyperthermia in several clinical studies is proof that hyperthermia yields a clinically relevant benefit $(20,27,28)$.

\section{AUTHOR CONTRIBUTIONS}

JC and HK contributed conception and design of the study. JC wrote the first draft of the manuscript. HK wrote sections of the manuscript. All authors contributed to manuscript revision, read, and approved the submitted version.
pH environment to hyperthermia. Int J Hyperthermia. (2003) 19:507-19. doi: 10.1080/0265673031000078697

5. Vaupel P, Kelleher DK. Blood flow and associated pathophysiology of uterine cervix cancers: characterisation and relevance for localised hyperthermia. Int J Hyperthermia. (2012) 28:518-27. doi: 10.3109/02656736.2012.699134

6. Peeken JC, Vaupel P, Combs SE. Integrating hyperthermia into modern radiation oncology: what evidence is necessary? Front Oncol. (2017) 7:132. doi: 10.3389/fonc.2017.00132

7. Dewhirst MW, Vujaskovic Z, Jones EL, Thrall DE. Re-setting the biological rationale for thermal therapy. Int J Hyperthermia. (2005) 21:77990. doi: 10.1080/02656730500271668

8. Elming PB, Soerensen BS, Oei AL, Franken NA, Crezee J, Overgaard J, et al. Hyperthermia: the optimal treatment to overcome radiation resistant hypoxia. Cancers. (2019) 11:60. doi: 10.3390/cancers11010060 
9. Gaitanaki C, Mastri M, Aggeli IK, Beis I. Differential roles of p38-MAPK and JNKs in mediating early protection or apoptosis in the hyperthermic perfused amphibian heart. J Exp Biol. (2008) 211:2524-32. doi: 10.1242/jeb.018960

10. Song CW, Park H, Griffin RJ. Improvement of tumor oxygenation by mild hyperthermia. Radiat Res. (2001) 155:515-28. doi: 10.1667/0033-7587 (2001) 155[0515:IOTOBM]2.0.CO;2

11. Secomb TW, Hsu R, Ong ET, Gross JF, Dewhirst MW. Analysis of the effects of oxygen supply and demand on hypoxic fraction in tumors. Acta Oncol. (1995) 34:313-6. doi: 10.3109/02841869509093981

12. van den Tempel N, Laffeber C, Odijk H, van Cappellen WA, van Rhoon GC, Franckena $\mathrm{M}$, et al. The effect of thermal dose on hyperthermia-mediated inhibition of DNA repair through homologous recombination. Oncotarget. (2017) 8:44593-604. doi: 10.18632/oncotarget.17861

13. Oei AL, Vriend LE, Crezee J, Franken NA, Krawczyk PM. Effects of hyperthermia on DNA repair pathways: one treatment to inhibit them all. Radiat Oncol. (2015) 10:165. doi: 10.1186/s13014-015-0462-0

14. Crezee H, van Leeuwen CM, Oei AL, Stalpers LJ, Bel A, Franken NA, et al. Thermoradiotherapy planning: integration in routine clinical practice. Int $J$ Hyperthermia. (2016) 32:41-9. doi: 10.3109/02656736.2015.1110757

15. Overgaard J. Simultaneous and sequential hyperthermia and radiation treatment of an experimental tumor and its surrounding normal tissue in vivo. Int $J$ Radiat Oncol Biol Phys. (1980) 6:1507-17. doi: 10.1016/0360-3016(80)90008-5

16. Cihoric N, Tsikkinis A, van Rhoon G, Crezee H, Aebersold DM, Bodis S, et al. Hyperthermia-related clinical trials on cancer treatment within the ClinicalTrials.gov registry. Int J Hyperthermia. (2015) 31:60914. doi: 10.3109/02656736.2015.1040471

17. Datta NR, Gomez Ordonez S, Gaipl US, Paulides MM, Crezee H, Gellermann J, et al. Local hyperthermia combined with radiotherapy and-/ or chemotherapy: recent advances and promises for the future. Cancer Treat Rev. (2015) 41:742-53. doi: 10.1016/j.ctrv.2015.05.009

18. van der Zee J, Gonzalez GD, van Rhoon GC, van Dijk JD, van Putten WL, Hart AA. Comparison of radiotherapy alone with radiotherapy plus hyperthermia in locally advanced pelvic tumours: a prospective, randomised, multicentre trial. Dutch Deep Hyperthermia Group. Lancet. (2000) 355:111925. doi: 10.1016/S0140-6736(00)02059-6

19. Datta NR, Stutz E, Gomez S, Bodis S. Efficacy and safety evaluation of the various therapeutic options in locally advanced cervix cancer: a systematic review and network meta-analysis of randomized clinical trials. Int $\mathrm{J}$ Rad Oncol Biol Phys. (2019). 103:411-37. doi: 10.1016/j.ijrobp.2018.09.037

20. Van Leeuwen CM, Oei AL, Chin KW, Crezee J, Bel A, Franken NA, et al. A short time interval between radiotherapy and hyperthermia reduces in-field recurrence and mortality in women with advanced cervical cancer. Radiat Oncol. (2017) 12:75. doi: 10.1186/s13014-017-0813-0

21. Kroesen M, Mulder HT, van Holthe JML, Aangeenbrug AA, Mens JWM, van Doorn HC, et al. The effect of the time interval between radiation and hyperthermia on clinical outcome in 400 locally advanced cervical carcinoma patients. Front Oncol. (2019) 9:134. doi: 10.3389/fonc.2019.00134
22. Kroesen M, Mulder HT, Van Rhoon GC, Franckena M. Response to: The Impact of the Time Interval between Radiation and Hyperthermia on Clinical Outcome in Patients with Locally Advanced Cervical Cancer. Front Oncol. (2019) 9:1387. doi: 10.3389/fonc.2019. 01387

23. Crezee H, Kok HP, Oei AL, Franken NAP, Stalpers LJA. The impact of the time interval between radiation and hyperthermia on clinical outcome in patients with locally advanced cervical cancer. Front Oncol. (2019) 9:412. doi: $10.3389 /$ fonc. 2019.00412

24. Van Leeuwen CM, Oei AL, Ten Cate R, Franken NA, Bel A, Stalpers LJ, et al. Measurement and analysis of the impact of time-interval, temperature and radiation dose on tumour cell survival and its application in thermoradiotherapy plan evaluation. Int J Hyperthermia. (2018) 34:308. doi: 10.1080/02656736.2017.1320812

25. Notter M, Piazena H, Vaupel P. Hypofractionated re-irradiation of largesized recurrent breast cancer with thermography-controlled, contact-free water-filtered infra-red-A hyperthermia: a retrospective study of 73 patients. Int J Hyperthermia. (2017) 33:227-36. doi: 10.1080/02656736.2016.12 35731

26. Lutgens LC, Koper PC, Jobsen JJ, van der Steen-Banasik EM, Creutzberg CL, van den Berg HA, et al. Radiation therapy combined with hyperthermia versus cisplatin for locally advanced cervical cancer: results of the randomized RADCHOC trial. Radiother Oncol. (2016) 120:378-82. doi: 10.1016/j.radonc.2016.02.010

27. Kroesen M, Mulder HT, Van Holthe JM, Aangeenbrug AA, Mens JW, Van Doorn HC, et al. Confirmation of thermal dose as a predictor of local control in cervical carcinoma patients treated with state-of-the-art radiation therapy and hyperthermia. Radiother Oncol. (2019) 140:1508. doi: 10.1016/j.radonc.2019.06.021

28. Franckena M, Fatehi D, de Bruijne M, Canters RA, van Norden Y, Mens JW, et al. Hyperthermia dose-effect relationship in 420 patients with cervical cancer treated with combined radiotherapy and hyperthermia. Eur J Cancer. (2009) 45:1969-78. doi: 10.1016/j.ejca.2009.03.009

Conflict of Interest: The authors declare that the research was conducted in the absence of any commercial or financial relationships that could be construed as a potential conflict of interest.

The reviewer $\mathrm{MH}$ declared a past co-authorship with several of the authors JC and HK to the handling Editor.

Copyright (c) 2020 Crezee, Oei, Franken, Stalpers and Kok. This is an open-access article distributed under the terms of the Creative Commons Attribution License (CC $B Y)$. The use, distribution or reproduction in other forums is permitted, provided the original author(s) and the copyright owner(s) are credited and that the original publication in this journal is cited, in accordance with accepted academic practice. No use, distribution or reproduction is permitted which does not comply with these terms. 